\title{
The Influence of Job Autonomy on Employee's Thriving at Work: An Innovative Theoretical Framework
}

\author{
Zhihui Li \\ School of Business Administration, South China University of Technology, Guangzhou, China \\ Email: 397469192@qq.com
}

How to cite this paper: Li, Z.H. (2018) The Influence of Job Autonomy on Employee's Thriving at Work: An Innovative Theoretical Framework. Journal of Service Science and Management, 11, 618-630. https://doi.org/10.4236/jssm.2018.116042

Received: November 14, 2018

Accepted: December 15, 2018

Published: December 19, 2018

Copyright $\odot 2018$ by author and Scientific Research Publishing Inc. This work is licensed under the Creative Commons Attribution International License (CC BY 4.0).

http://creativecommons.org/licenses/by/4.0/

\begin{abstract}
For enterprises facing a rapidly changing external environment, employee's thriving at work may be the key to sustained success. After sorting out the current research situation of scholars home and abroad, several shortcomings emerge. In this paper a model of job autonomy affecting employees' thriving at work through psychological capital is constructed, and the internal mechanism of job autonomy affecting employees' thriving at work is investigated, which is helpful to grasp the impact of job autonomy on employees' thriving at work more comprehensively.
\end{abstract}

\section{Keywords}

Job Autonomy, Thriving at Work, Psychological Capital

\section{Research Background}

With the continuous development and progress of science and technology, the popularity of mobile Internet applications, the emergence of new technologies such as big data and cloud computing, enterprises and individuals are facing a rapidly changing external environment. With the globalization of knowledge economy and the transformation of market economy, how to keep employees in a state of active learning and sustained vitality is the key to help enterprises cope with the above changes successfully, to achieve sustainable development and to gain a foothold in the constantly changing market environment. Thriving at work, as a positive mental state of employees, is a yardstick to measure personal growth and progress. The more thriving employees experience, the easier they will be full of vitality and motivation in their work, and the more they will continue to learn and grow. 
After sorting out the current research situation of scholars home and abroad, we find some shortcomings. Firstly, thriving at work is a relatively new variable put forward by foreign scholars in recent years. At present, foreign scholars have put forward a theoretical model of thriving at work to guide future research, but domestic scholars have relatively little research on thriving at work, especially lack of empirical research on job prosperity in Chinese corporate culture. Secondly, the existing research on the influencing factors of thriving at work in China is very limited, involving only a few antecedent variables, and the only antecedent variables are mainly leadership style and behavior, or perceived organizational support as independent variables, but not job characteristics as independent variables. Hackman's and Oldham's five core dimensions of job have the most influence on the definition of job characteristics, and a considerable number of studies on job characteristics are based on this view. The research of Hackman and Oldham (1975) points out that job characteristics include five core dimensions: job integrity, skill diversity, job autonomy, job feedback and job importance, and adds two auxiliary dimensions: feedback from others and dealing with relationships with others. Among them, job autonomy refers to the degree to which employees can arrange their work schedule and methods independently.

\section{Literature Review and Theoretical Basis}

This chapter mainly reviews and combs the relevant research variables, in order to provide literature support for hypothesis deduction and model building. By combing and deducing the causal relationship among job autonomy, psychological capital and thriving at work, we can get the hypothesis and model construction of this paper (as shown in Figure 1).

\subsection{Thriving at Work}

The concept of "thriving" has been explored in many disciplines. In medicine, "failing to thrive" refers to infaust growth and development of infants and young children or the elderly, mental malaise, inconvenience, indifference or lack of appetite (Bakwin, 1949) [1]. Psychologically, "thriving" refers more to psychological growth than physical growth, including not only individual survival or barely surviving (Benson and Scales, 2009) [2], but also individual growth (Joseph and Linley, 2008) [3], or in a growth situation (Thomas and Hall, 2008) [4].

The research on thriving can be traced back to the study of Maslow, Alderfer and other scholars in the middle of twentieth Century. However, the concept of "thriving at work" was first put forward by Spreitzer et al. in 2005, which has a

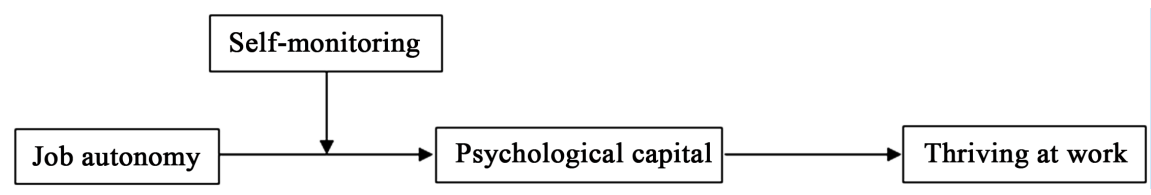

Figure 1. Theoretical framework. 
great theoretical value in the field of positive psychology and positive organizational behavior. In the view of Spreitzer et al. (2005) [5], thriving at work is a psychological state, a subjective feeling and experience of individuals, with both vitality and learning dimensions. These two dimensions essentially reflect the emotional (vitality) and cognitive (learning) psychological experience in personal growth. On the one hand, vitality refers to a person who has positive energy and feels positive emotion, enthusiasm and upward power (Nix et al., 1999) [6]; on the other hand, learning refers to a person's process of acquiring knowledge, applying knowledge and skills and feeling self-growth (Elliott \&amp; Dweck, 1988) [7]. Although the connotation of thriving at work is still under discussion, the academic circles have reached a consistent conclusion that thriving at work is a two-dimensional structure consisting of learning dimension and vitality dimension. Vitality and learning are important components of thriving at work. Both dimensions predict personal growth and development to a certain extent. Only by combining these two dimensions can the individual experience thriving. If an individual lacks vitality and keeps learning, he will soon feel exhausted. Similarly, if he lacks learning experience, even if he is energetic, he will be hindered from developing because he cannot feel his growth and will not achieve thriving.

With Spreitzer et al. (2005) [5] applying thriving at work to the field of management, the exploration of pre-dependent variables of thriving at work has begun. The antecedent variables of thriving at work mainly focus on two aspects: organizational factors and individual differences.

The organizational antecedents include organizational environment, organizational resources, organizational capability, organizational mechanism and organizational performance. Studies by Spreitzer and Path (2013) [8] suggest that the degree of thriving at work can be impaired by severe fluctuations and changes in the working environment. Similarly, extra work can divert employees' attention from their work and reduce their mental resources to focus on accomplishing tasks. Wu Jiangqiu et al. (2015) [9] argued that social support had a positive impact on the realization of thriving at work in empirical research. Social support includes visible and practical support (such as direct material assistance, advice and persuasion, social network), and emotional support (such as being understood, respected experience, satisfaction, trust) experienced. Niessen, Spreitzer and other studies have shown that knowledge resources have a positive impact on the realization of thriving, promote individual vitality and learning experience, and enable individuals to achieve the psychological state of thriving. Spreitzer and Sutcliffe et al. (2005) [5] pointed out in the social embedding model of thriving at work that positive emotional resources and knowledge resources are both important factors for thriving at work. In the workplace, the positive relationships among colleagues and between colleagues and leaders are of great significance to the emergence of individual thriving. Paterson, Luthans and Jeung (2014) [10] found that employees who felt organizational support were more likely to prosper because they were more inclined to abide by the principle 
of reciprocity in social exchange. Research by Spreitzer, Porath and Gibson (2012) [11] found that positive meaningful resources achieve individual thriving by promoting positive behavior. Spreitzer et al. (2005) [5] argued that information sharing is also conducive to the formation of positive work behavior, and positive work behavior will promote the realization of individual thriving. Studies of Carmeli and Preitzer (2009) [12] show that an atmosphere of trust and respect promotes employees' experience of vitality and learning. In addition, Jenkins (2010) [13] studies also believe that both organizational transparency and organizational inclusiveness have a positive impact on the realization of individual thriving. Wu Jiangqiu (2015) [9] Empirical research found that there is a positive correlation between organizational empowerment and supervision guidance and thriving. Spreitzer (2012) [14] Research shows that when people are directed by leaders or forced by institutions to do things, they will not thrive in their work. They thrive only when people are in a supportive environment of discretion. Jenkins (2010) [13] pointed out in the case study that challenging work can also promote individual thriving. Wu Jiangqiu et al. (2015) [9] believes that career development resources will motivate employees to generate thriving. Several studies by Spreitzer point out that individuals are more likely to thrive in the following three types of organizational norms: organizational norms that support flexible decision-making mechanisms, organizational norms that support extensive information sharing, and organizational norms that have trust and respect. Meanwhile, Carmeli and Preitzer (2009) [12] found that a pluralistic organizational climate is an extension of an atmosphere that encourages respect and trust, which enhances learning and vitality in thriving.

Individual level research mainly includes individual characteristics, individual behavior, personal transcendence and learning, psychological resources, etc. Spreitzer and Porath (2012) [14] found that proactive personality was associated with thriving. Research by Porath et al. (2012) [11] shows that people with low self-esteem tend to attribute negative outcomes too much to personal failure, which hinders their learning and vitality, while individuals with self-esteem are more likely to experience thriving. Carmeli and Russo (2015) [15] believe that individual micro-emotions include gratitude, sympathy, emotional expression, and have a positive impact on individual thriving through the process of individual positive attention, work and family gain. People with stable emotions are more likely to thrive. Spreitzer and Path (2012) [14] argue that people with high learning goal orientation and high performance certification guidance are more likely to thrive. Recent studies by Paterson et al. (2014) [10] show that psychological capital is a pioneer of thriving at work. Research by Russo, Buonocore and Carmeli (2015) [15] reveals the indirect process of individual thriving through psychological accessibility and work-family benefits. In the personal growth integration model proposed by Spreitzer and Path (2013) [8], three important factors of self-determination (sense of autonomy, sense of competence and sense of belonging) can lead to a thriving psychological experience. People with high self-efficacy are more likely to actively participate in tasks, which can 
generate vitality and improve the likelihood of learning, and ultimately achieve thriving (Porath et al., 2012; Wu Jiangqiu, 2015 [9]. Geiger (2013) [16] believes that subjective well-being (including five dimensions: sense of belonging, meaning and purpose, growth and maturity, flexibility and autonomy, participation and influence) can foster a higher level of thriving. At the same time, Boyd (2015) [17] found that team participation and community responsibility can also trigger the experience of individual thriving.

\subsection{A Social Embeddedness Model for Thriving at Work}

Spreitzer et al. (2005) [5] constructs a social embedded model of thriving at work. The social embeddedness model describes how work situations achieve thriving at work through individual's active work behavior. The model considers that organizational factors are important forces contributing to or consuming thriving at work. When individuals are in certain organizational situations, they are more likely to experience thriving. At the organizational level, the model describes two types of organizational factors: more stable organizational context characteristics (decision-making power, information sharing, trust and respect organizational climate) and more active work resources (knowledge, positive meaning, positive emotional resources, positive relationship resources). At the individual level, the model considers that the individual's active work behavior (task focus, active exploration, attention correlation) is an individual's purposeful active behavior. Task focus is to transfer all your actions and energies to your work, focusing on the current state of work. The degree of task focus has a positive impact on the learning dimension. Active exploration refers to the development of new ways of working, while attention to relevance refers to the strengthening of contacts with other people in the workplace. The individual's behavior has a positive impact on the realization of thriving at work.

First of all, when an individual is in a position to encourage independent decision-making, employees are given the right to make decisions, and they can freely arrange the way of work and the behavior they take. Members of an organization share all the information of the organization extensively, and establish a mutual respect and respect between members. When trust is organized, it is more likely to arouse individual initiative. Secondly, a series of resources produced in the work are raw materials produced by motivations. The change of these resources is dynamic. Individuals will consume these resources in the process of generating motivational work behavior, but the occurrence of new motivational behavior will promote the generation of new positive resources in organizations. Therefore, Spreitzer et al. (2005) [5] argues that there is a virtuous circular relationship between resources and motivational work behavior. Then, active behavior is the engine to promote thriving at work. Task focus, active exploration and attention to related behavior can promote learning and vitality experience. At the same time, the experience of thriving will also promote the individual's active work behavior. The thriving individual will work more actively, strengthen the relationship with the surrounding individuals, and form a 
virtuous circle.

This model demonstrates how a series of active work behaviors can be cultivated by specific organizational characteristics and resources generated in work. Active work behavior is an important factor to induce thriving at work. Initiative work behavior can also promote the formation of different kinds of positive organizational resources, in order to further promote the cultivation of initiative work behavior. Organizational characteristics, proactive behaviors, and resources generated in the workplace can contribute to the thriving of employees' work.

\subsection{The Relationship between Job Autonomy and Thriving at Work}

Thriving at work is a psychological state with two dimensions of vitality and learning. These two dimensions essentially reflect the emotional (vitality) and cognitive (learning) psychological experience in personal growth. According to the social embedding model of thriving at work, organizational factors are the important forces contributing to or consuming thriving at work. When individuals are in certain organizational situations, they are more likely to experience thriving. These specific organizational contexts include decision-making situations. When an individual is in an organization that encourages autonomous decision-making, gives employees certain decision-making rights, and can freely arrange the way of work and adopt the behavior, it is easier to trigger the individual's initiative behavior, which is an important factor to induce the thriving at work. Therefore, decision-making power can help employees achieve thriving at work by promoting their active work behavior.

Decision-making power provides employees with freedom and choice of how to work (Spreitzer, 2005) [5]. Job autonomy refers to the degree of employees' autonomous scheduling of work progress and methods. Therefore, the autonomy of work can reflect the decision-making power of employees in the organization. First, autonomous performance affects the task focus of employees. When employees perceive less autonomy, their task focus tends to relax prematurely, especially in the face of work challenges (Wood \&amp; Bandura, 1989) [18]. On the contrary, when employees feel autonomous and able to manage their job responsibilities, they are more likely to actively work and continuously apply their skills (Bandura, 1988) [19]. Secondly, when employees can choose how to work, they are more likely to find new ways of working (Amabile, 1993) [20]. Being a decision maker can help employees build new skills and self-efficacy, make them more willing to take risks and explore new opportunities (Spreitzer, 1996) [21], that is, self-determination promotes employees' explore behavior. Finally, situations that encourage decision-making power can promote attention-related behavior. Being a member of an organization's decision-maker gives employees a sense of being associated with others and makes them pay more attention to the work of others. This encourages employees to strengthen their contacts with others in the workplace (Spreitzer, 2005), which promotes employees' attention 
to related behaviors.

When employee's job autonomy increases, their task focus, exploration and attention to relevant behavior will be promoted, and these active work behavior is an important factor to promote thriving at work. That is to say, job autonomy promotes employee's thriving at work by promoting initiative work behavior. Liu and Bernklug's (2013) [22] empirical study of 928 directors of social services in nursing homes also found that job autonomy was positively correlated with thriving at work. As thriving at work has two dimensions of learning and vitality, it is necessary to explore the role of job autonomy in promoting each dimension respectively, so as to clarify the relationship between job autonomy and thriving at work as much as possible. Therefore, this study considers that job autonomy is positively related to thriving at work, and proposes the following assumptions:

H1: job autonomy has positive predictive effect on thriving at work.

$\mathrm{H} 1 \mathrm{a}$ : job autonomy has positive predictive effect on the vitality dimension of thriving at work.

H1b: job autonomy plays a positive role in predicting the learning dimension of thriving at work.

\subsection{The Relationship between Work Autonomy and Psychological Capital}

According to Hackman and Oldham's work characteristic model, work autonomy has an important influence on employees' internal motivation, which affects three key psychological states of employees. These three key psychological states, as intermediary variables, can lead to positive personal and work outcomes, such as high internal motivation, high-quality performance, high efficiency, high satisfaction with work, low absenteeism and low turnover rate. The model considers that the work content itself has an intrinsic incentive effect on employees. This cycle mode enables employees to generate positive self motivation and then make the organization produce a virtuous circle. Work autonomy achieves the key psychological state through individual perception, thus improving the positive factor of individual psychological capital level.

Luthans and Youssef-Morgan (2017) [23] argue that a sense of control is essential for the formation of psychological capital. Work autonomy means that employees can control their work methods and progress, give them a sense of control, and achieve the necessary conditions of psychological capital. Avey (2014) [24] study of 1264 employees found that job characteristics are antecedents of psychological capital. Wang Fang and Zhang Hui (2016) [25], taking university librarians as the research object, analyzed various factors affecting psychological capital, and found that work autonomy has a significant positive impact on University librarians' psychological capital.

At present, there are few studies on the impact of work autonomy on psychological capital, but some studies have shown that work autonomy has a positive impact on individual self-efficacy, optimism and other psychological abilities. 
Studies by Llorens, Schaufeli, Bakker and Salanova (2007) [26] point out that autonomy can improve individual self-efficacy; Xanthopoulou, Bakker and Demerouti (2007) [27] found that autonomy can stimulate employees' self-efficacy, based on organizational self-esteem and optimism, and make them feel in control of the work environment, and be satisfied and confident in completing work. Xanthopoulou, Bakker and Demerouti (2012) [28] used the method of log research to conduct a survey of 52 employees for five consecutive working days. The results showed that autonomy had a positive effect on self-efficacy, self-esteem and optimism, which further supported their previous research. As a second-order latent factor concept, psychological capital also has a positive impact on psychological capital on the basis of the influence of autonomy on its various dimensions.

Therefore, this study holds that job autonomy is positively related to psychological capital and makes the following assumptions:

$\mathrm{H} 2$ : job autonomy has a positive predictive effect on psychological capital.

\subsection{The Relationship between Psychological Capital and Thriving at Work}

According to the Theory of Resource Preservation, people attach importance to resources. After obtaining resources, people will use these resources to obtain more resources. In order to maximize the use of resources, people often use resources in the workplace. According to the "value-added spiral" effect, once a resource is successfully acquired, the individual is likely to get the next new resource with the help of the former resource. The spiral effect of resource acquisition can strengthen the individual's behavior tendency, and make the individual with more resources more inclined to invest a lot of existing resources in order to double the acquisition of new resources. As a collection of a series of positive psychological resources, psychological capital can help individuals improve their motivation and ability to act and apply it to their work. In order to maximize the use of resources, individuals must also release and utilize psychological capital by taking active actions. Employees with higher level of psychological capital have more resources and tend to invest existing resources in order to double their access to new resources. This kind of investment may trigger employees' initiative work behavior (task focus, exploration, attention related) and ultimately achieve thriving at work.

Paterson, Luthans and Jeung (2014) [10] pointed out that employees with higher psychological capital have more confidence in successfully accomplishing work tasks, stronger ability of using goal orientation and actively plan various ways to achieve goals. They persist in meeting difficulties and return positive organizational performance. Through a study of 198 employees, it was found that psychological capital ultimately promotes thriving at work by promoting task focus and attention. Psychological capital can also significantly affect employees' learning behavior through learning ability. The higher the level of psy- 
chological capital, the more willing they are to express their ideas and share knowledge with other members, the more learning behavior they have. For example, Yang Yan (2010) confirmed that psychological capital can influence organizational and team learning. Employees with high levels of hope have clear goals of knowledge acquisition, sharing, diffusion and creation, and have specific paths to achieve these goals in combination with the characteristics of knowledge, so as to promote learning. Optimism is positively correlated with satisfaction, positive mood and self-esteem (Chang, 1996). In organizational context, the level of optimism affects employees' expectations of future organizational learning and innovation, and promotes employees to constantly adjust their learning state under low-level anxiety. Resilience in the organization can improve learning ability, solve the challenges and novelty of the process is also the process of employees' resilience to play a role. Therefore, the dimensions of employees' psychological capital have an impact on the learning dimension of job prosperity. In addition, individuals with high psychological capital show positive emotions. They are not worried about bad job evaluation, so they tend to devote more time and energy to their work. For example, Li Xiaoyan (2013) confirmed that psychological capital can influence individual's work behavior. Employees with higher level of psychological capital are more energetic in their work engagement and have a strong willingness to learn. Therefore, psychological capital has a positive effect on the vitality dimension of thriving at work.

Therefore, this study holds that psychological capital is positively related to thriving at work and makes the following assumptions:

H3: psychological capital has positive predictive effect on thriving at work

\subsection{Moderating Effect of Self-Monitoring}

The concept of self-monitoring originates from personality psychology, which mainly reflects the differences in the tendency and ability of individuals to supervise and control their self-presentation and behavior (Snyder, 1974) [29]. Because the situation which provides clues to guide high self-monitors' behavior is constantly changing, so their performance change with the situation. On the contrary, low self monitors show relative consistency in different situations. Self monitoring personality is closely related to attitude and behavior in organizational context. Many studies have found that self-monitoring plays a moderating role in the relationship between antecedent variables and attitudes and behavioral variables.

This study holds that when job autonomy increases, employees with high self-monitoring are more likely to adjust their work according to this situation, maximize the use of this resource to serve themselves, obtain more resources, and thus improve the level of psychological capital. The behavior of employees with low self-monitoring shows relative consistency in different situations. Even if their work autonomy increases, they may not adjust their working methods and maximize the use of this resource. The improvement of their psychological 
capital may be less than that of employees with high self-monitoring.

Therefore, this study considers that self-monitoring plays a moderating role in the relationship between job autonomy and psychological capital, and makes the following assumptions:

H4: self monitoring plays a regulatory role in the relationship between work autonomy and psychological capital.

\section{Theoretical Framework}

By reviewing the previous literature on the social embedding model of thriving at work and Resource Preservation Theory, this paper logically combs and deduces the impact of job autonomy on thriving at work, and further discusses the role of psychological capital as a process path of job autonomy in promoting thriving at work. As well as the moderating role of self-monitoring in the relationship between job autonomy and thriving at work, the hypothesis and model of this study are formed, as shown in Figure 1.

\section{Conclusions}

For enterprises facing a rapidly changing external environment, employee's thriving at work may be the key to sustained success. At present, many scholars pay attention to the research topic of thriving at work. However, the relevant research is still in its infancy. The research results mainly focus on the influence of a few antecedent variables, while ignoring the impact of job characteristics, especially job autonomy. By reviewing the previous literature on the social embedding model of thriving at work and Resource Preservation Theory, this paper logically combs and deduces the impact of job autonomy on thriving at work, and further discusses the role of psychological capital as a process path of job autonomy in promoting thriving at work.

The article has relatively outstanding contributions. The theoretical contribution of this study lies mainly in:

Firstly, a model of job autonomy affecting employees' thriving at work through psychological capital is constructed, and the internal mechanism of job autonomy affecting employees' thriving at work is investigated, which is helpful to grasp the impact of job autonomy on employees' thriving at work more comprehensively.

Secondly, from the perspective of resource preservation, based on the social embedding model of thriving at work, psychological capital is used to explain the path of job autonomy affecting thriving at work, which fills the gap of empirical research on the impact of job autonomy on thriving at work in China at this stage.

Finally, it verifies the applicability of the social embedding model of work prosperity in Chinese context, and provides theoretical guidance for human resource management practice of Chinese enterprises, especially for employee incentives. 
Based on the theory of resource preservation and existing research assumptions, this study takes psychological capital as a mediating variable between job autonomy and employee thriving at work, builds a theoretical model to make up for the deficiencies of existing research, and opens up a new way of thinking for future related research.

The practical contribution of this study lies in:

As a human resource management practice, job design has been widely used in enterprise management practice, which has a great impact on employee behavior. It is self-evident that thriving at work of employees is the key to help enterprises to achieve sustainable development and gain a foothold in the constantly changing market environment. Therefore, how to stimulate the thriving at work of employees through the improvement of job autonomy is an urgent question for enterprise managers to answer. In this study, psychological capital as a mediating variable, exploring the impact of job autonomy on employee thriving at work, for better organizational design work, stimulate employee thriving at work, has a certain reference significance.

\section{Conflicts of Interest}

The authors declare no conflicts of interest regarding the publication of this paper.

\section{References}

[1] Bakwin, H. (1949) Emotional Deprivation in Infants. Journal of Pediatrics, 35, 512-521. https://doi.org/10.1016/S0022-3476(49)80071-0

[2] Benson, P.L. and Scales, P.C. (2009) The Definition and Preliminary Measurement of Thriving in Adolescence. Journal of Positive Psychology, 4, 85-104. https://doi.org/10.1080/17439760802399240

[3] Joseph, S. and Linley, P.A. (2008) Trauma, Recovery, and Growth.

[4] Thomas, S.P. and Hall, J.M. (2008) Life Trajectories of Female Child Abuse Survivors Thriving in Adulthood. Qualitative Health Research, 18, 149. https://doi.org/10.1177/1049732307312201

[5] Spreitzer, G., Sutcliffe, K., Dutton, J., et al. (2005) A Socially Embedded Model of Thriving at Work. Organization Science, 16, 537-549. https://doi.org/10.1287/orsc.1050.0153

[6] Nix, G.A., Ryan, R.M., Manly, J.B., et al. (1999) Revitalization through Self-Regulation: The Effects of Autonomous and Controlled Motivation on Happiness and Vitality. Journal of Experimental Social Psychology, 35, 266-284. https://doi.org/10.1006/jesp.1999.1382

[7] Elliott, E.S. and Dweck, C.S. (1988) Goals: An Approach to Motivation and Achievement. Journal of Personality \& Social Psychology, 54, 5-12. https://doi.org/10.1037/0022-3514.54.1.5

[8] Spreitzer, G.M. and Porath, C. (2013) Self-Determination as a Nutriment for Thriving: Building an Integrative Model of Human Growth at Work. Ann Arbor.

[9] Wu, J.Q., Huang, P.L. and Yan, D. (2015) The Generation of Thriving at Work and Its Impact on Innovation Performance: An Empirical Study of High-Tech Enter- 
prises in Guangdong Province. Ruan Ke Xue, (7): 110-113.

[10] Paterson, T.A., Luthans, F. and Jeung, W. (2014) Thriving at Work: Impact of Psychological Capital and Supervisor Support. Journal of Organizational Behavior, 35, 434-446. https://doi.org/10.1002/job.1907

[11] Porath, C., Spreitzer, G., Gibson, C., et al. (2012) Thriving at Work: Toward Its Measurement, Construct Validation, and Theoretical Refinement. Journal of Organizational Behavior, 33, 250-275. https://doi.org/10.1002/job.756

[12] Carmeli, A. and Spreitzer, G.M. (2011) Trust, Connectivity, and Thriving: Implications for Innovative Behaviors at Work. Journal of Creative Behavior, 43, 169-191. https://doi.org/10.1002/j.2162-6057.2009.tb01313.x

[13] Jenkins, P.K. (2010) A Case Study of Collective Thriving at Work. Dissertations \& Theses - Gradworks.

[14] Spreitzer, G. and Porath, C. (2012) Creating Sustainable Performance. Harvard Business Review, 90, 92-99.

[15] Carmeli, A. and Russo, M. (2016) The Power of Micro-Moves in Cultivating Regardful Relationships: Implications for Work-Home Enrichment and Thriving. Human Resource Management Review, 26, 112-124. https://doi.org/10.1016/j.hrmr.2015.09.007

[16] Geiger, L. (2013) Leading towards Well-Being: Exploring Organizational Climate, Leadership and Individual Factors That Relate to Thriving at Work. Dissertations Theses.

[17] Boyd, N.M. (2015) Introducing Thriving at Work to the Field of Community Psychology. Journal of Community Psychology, 43, 794-809. https://doi.org/10.1002/jcop.21752

[18] Wood, R. and Bandura, A. (1989) Social Cognitive Theory of Organizational Management. Academy of Management Review, 14, 361-384. https://doi.org/10.5465/amr.1989.4279067

[19] Bandura, A. (1989) Self-Regulation of Motivation and Action through Internal Standards and Goal Systems. Goal Concepts in Personality \& Social Psychology, 14, 517-524.

[20] Amabile, T.M. (1993) Motivational Synergy: Toward New Conceptualizations of Intrinsic and Extrinsic Motivation in the Workplace. Human Resource Management Review, 3, 185-201. https://doi.org/10.1016/1053-4822(93)90012-S

[21] Ryan, R.M. and Deci, E.L. (2000) Self-Determination Theory and the Facilitation of Intrinsic Motivation, Social Development, and Well-Being. American Psychologist, 55, 68-78. https://doi.org/10.1037/0003-066X.55.1.68

[22] Liu, J. and Bern Klug, M. (2013) Nursing Home Social Services Directors Who Report Thriving at Work. Journal of Gerontological Social Work, 56, 127-145. https://doi.org/10.1080/01634372.2012.750255

[23] Luthans, F. and Youssefmorgan, C.M. (2017) Psychological Capital: An Evidence-Based Positive Approach. Annual Review of Organizational Psychology and Organizational Behavior, 4, 339-366.

[24] Avey, J.B., Luthans, F., Smith, R.M., et al. (2010) Impact of Positive Psychological Capital on Employee Well-Being over Time. Journal of Occupational Health Psychology, 15, 17-28. https://doi.org/10.1037/a0016998

[25] Wang, F. and Zhang, H. (2016) An Empirical Study on the Influencing Factors of University Librarians' Psychological Capital. Shandong Library Journal, No. 4, 10-16. 
[26] Llorens, S., Schaufeli, W., Bakker, A., et al. (2007) Does a Positive Gain Spiral of Resources, Efficacy Beliefs and Engagement Exist? Computers in Human Behavior, 23, 825-841. https://doi.org/10.1016/j.chb.2004.11.012

[27] Xanthopoulou, D., Bakker, A.B., Demerouti, E., et al. (2007) The Role of Personal Resources in the Job Demands-Resources Model. International Journal of Stress Management, 14, 121-141. https://doi.org/10.1037/1072-5245.14.2.121

[28] Xanthopoulou, D., Bakker, A.B., Demerouti, E., et al. (2012) A Diary Study on the Happy Worker: How Job Resources Relate to Positive Emotions and Personal Resources. European Journal of Work \& Organizational Psychology, 21, 489-517. https://doi.org/10.1080/1359432X.2011.584386

[29] Snyder, M. (2015) Self-Monitoring of Expressive Behavior. Journal of Personality \& Social Psychology, 30, 526-537. https://doi.org/10.1037/h0037039 